\title{
ESCALA DE VALORES DE APRENDIZAGEM EM ORGANIZAÇÕES: validação de um instrumento de medida
}

\section{1- Antonio Isidro da Silva Filho*}

Doutor em Administração pela Universidade de Brasília - UnB, Brasília/DF, Brasil.

Professor do Programa de Pós-graduação em Administração da Universidade de Brasília - UnB, Brasília/DF, Brasil. antonio.isidro.filho@gmail.com

http://lattes.cnpq.br/0218572658627924 


\title{
ESCALA DE VALORES DE APRENDIZAGEM EM ORGANIZAÇÕES: VALIDAÇÃO DE UM INSTRUMENTO DE MEDIDA
}

\section{RESUMO}

O presente estudo teve por objetivo o desenvolvimento e validação da Escala de Valores de Aprendizagem em Organizações (EVAO). A partir da Learning Values Scale de Ellis et al. (1999), composta dos fatores responsabilidade, transparência, informação válida e orientação, foi realizada a tradução dos itens da língua inglesa para o português e adequação de linguagem para a cultura brasileira. Feito isso, realizou-se a análise de conteúdo (construto) e semântica dos itens, sendo que dos 35 itens originais 25 permaneceram para validação empírica da escala. 522 funcionários de uma instituição financeira com sede em Brasília/DF responderam ao instrumento de pesquisa. Após as análise fatoriais, identificou-se a melhor solução (rotação Oblimin) com 3 fatores, que revelou o índice Kaiser-Meyer-Olkin (KMO) de 0,93. Os fatores foram denominados: Responsabilidade e Abertura à Aprendizagem (12 itens, $\alpha=0,90$ ), Transparência no Desempenho no Trabalho (4 itens, $\alpha=0,78)$ e Integridade e Igualdade no Trabalho $(9$ itens, $\alpha=0,85$ ). Concluindo o estudo, descreve-se recomendações para futuras pesquisas visando o melhoramento da escala validada, bem como a realização de estudos que verifiquem as relações entre valores de aprendizagem em organizações com outras variáveis da literatura de comportamento organizacional.

\section{Palavras-Chave}

Valores de Aprendizagem; aprendizagem em organizações; comportamento organizacional; escala de medida

\section{ORGANIZATIONAL LEARNING VALUES SCALE: VALIDATION OF MEASURE INSTRUMENT}

\begin{abstract}
The aim of this paper was to develop and to validate the Organizational Learning Values Scale (OLVS). Based on Learning Values Scale of Ellis et al. (1999), the items were translated from English language to Portuguese language. Thirty-five items were submitted to empirical validation and twenty-five items were confirmed. Five hundred and twenty-two employees of a financial organization were participated of this research. In the factorial analysis, the best solution was identified (Oblimin rotation, $\mathrm{KMO}=0,93$ ) with three factors. The factors were named: Responsibility and Opening to Learning (12 items, $\alpha=0,90$ ), Transparency in Work Performance (4 items, $\alpha=0,78)$ and Integrity and Equality at Work $(9$ items, $\alpha=$ $0,85)$. Finally, conclusions and recommendations for future research are presented and suggest the improvement of OLVS as well as to investigate the relationship between learning values and others organizational variables.
\end{abstract}

\section{Keywords}

Organizational Learning Values; Organizational Learning; Organizational Behavior; Measure Scale 


\section{Introdução}

A aprendizagem em contextos organizacionais tornou-se um tema que vem recebendo atenção de pesquisadores, acadêmicos e consultores nos últimos anos, com o intuito de se compreender esse processo e seus resultados. Segundo Wilpert (1995), algumas razões fizeram da aprendizagem em organizações um tema de interesse, tais como: reajustamento de políticas de pessoal em virtude de mudanças demográficas; alteração nas relações industriais em conseqüência de mudanças nos valores sociais; adaptação exigida por um ambiente globalmente competitivo; novas competências e repertórios comportamentais em função do rápido desenvolvimento tecnológico; propriedade dinâmica e integrativa do conceito de aprendizagem em organizações que o torna atrativo na área de comportamento organizacional.

Para Bastos, Gondim e Loiola (2004), capacidade de aprender permite que a organização identifique, processe e retenha conhecimentos, resultando em melhorias do processo decisório e capacidade de competição. Com a premissa de que variáveis organizacionais impactam o comportamento de uma organização, Lipshitz, Popper e Friedman (2002) destacam a aprendizagem em organizações enquanto um processo multifacetado que envolve fatores intervenientes em relação à sua ocorrência efetiva.

Dentre as diversas variáveis presentes no contexto organizacional, os valores de aprendizagem configuram-se como um dos determinantes da aprendizagem em organizações (POPPER; LIPSHITZ, 1998; LIPSHITZ; POPPER; FRIEDMAN, 2002), uma vez que permite o compartilhamento de crenças, valores, atitudes, papéis, suposições e comportamentos de indivíduos que permitem a real aprendizagem (ARMSTRONG; FOLEY, 2003). Sendo assim, este estudo objetivou descrever o processo de validação da Escala de Valores de Aprendizagem em Organizações. Para isso, abordou-se a percepção de funcionários de uma organização financeira acerca da ocorrência de comportamentos orientados à aprendizagem no ambiente de organizações.

O texto encontra-se organizado em quatro seções. A primeira discute aspectos teóricos da aprendizagem em organizações, enfatizando a variável valores de aprendizagem. A segunda seção aborda a metodologia empregada neste estudo para desenvolvimento e validação empírica da escala de medida. A seção seguinte apresenta os resultados e discussões, destacando os dados obtidos a partir das análises realizadas para validação da escala. E, por fim, conclusões e recomendações são descritas com o intuito de ressaltar a importância do estudo para a literatura, bem como destacar propostas de estudos futuros que contribuam para o desenvolvimento de um arcabouço teórico-metodológico cumulativo em relação à aprendizagem em organizações.

\section{Referencial Teórico}

O campo de estudos da aprendizagem em organizações é marcado pela diversidade conceitual estimulada pelo interesse de vários pesquisadores em compreender como esse fenômeno se dá em contextos organizacionais (EASTERBY-SMITH, 1997; POPPER; LIPSHITZ, 1998; EASTERBY-SMITH; ARAÚJO, 2001). Como conseqüência da proliferação de conceitos acerca da aprendizagem em organizações, Popper e Lipshitz (1998) destacam o debate da antropomorfização em que muitos autores discutem a apropriação de um fenômeno individual para o nível organizacional. Entretanto, alguns estudiosos propõem o uso do termo aprendizagem em organizações como uma metáfora que permite inferir a similaridade de processos de aprendizagem nos níveis individual, coletivo e organizacional (WEICK; WESTLEY, 1996, POPPER; LIPSHITZ, 1998; GHERARDI; NICHOLINI, 2003; BASTOS; GONDIM; LOIOLA, 2004).

Apesar das divergências conceituais presentes na literatura do campo da aprendizagem em organizações, é possível observar algumas convergências como ênfase na aprendizagem individual como alicerce da aprendizagem em organizações, a importância dada as interações sociais como meio de compartilhamento de conhecimentos e experiências, bem como o destaque ao papel da estrutura organizacional como elemento de suporte para a aprendizagem de indivíduos e organizações.

Com base nas afirmações de Easterby-Smith e Araújo (2001), a aprendizagem em organizações pode ser compreendida em duas dimensões, uma tangível e outra intangível. A dimensão tangível refere-se a aprendizagem como um fenômeno técnico, ou seja, um processo de transformação, interpretação e resposta a informações advindas dos ambientes internos e externos à organização. Essa dimensão é caracterizada pelos mecanismos de aprendizagem e gestão de informações e conhecimentos (NONAKA; TAKEUCHI, 1997; POPPER; LIPSHITZ, 1998; GARVIN, 2002; ISIDRO-FILHO, 2006). 
A dimensão intangível caracteriza-se pela ênfase na aprendizagem como um fenômeno social na medida em que evidencia como as pessoas atribuem significados a suas experiências no trabalho e os compartilham com seus pares em ambientes intra e interorganizacionais. Nesse sentido, importa destacar o papel da cultura organizacional como reguladora do pensar, sentir e agir de indivíduos, uma vez que o presente trabalho tem como objeto de estudo os valores de aprendizagem em organizações.

O termo cultura organizacional foi popularizado na literatura de gestão na década de 1980, com a noção de que a excelência da organização dependia das formas comuns de pensar, sentir e agir de seus membros (HOFSTEDE, 1991). Na visão de Hofstede et al.(1990), apesar da diversidade teórica, muitos estudiosos concordam que a cultura organizacional é: (a) holística; (b) determinada historicamente; (c) relacionada com os conceitos e estudos antropológicos; (d) construída socialmente; (e) intangível; (f) difícil de mudar. Complementando essa noção, Duncan (1989) afirma que a cultura apresenta três características: é aprendida, compartilhada e transmitida. Isso reforça que a cultura das organizações apresenta duas dimensões: objetiva e subjetiva.

Segundo Duncan (1989), a dimensão objetiva da cultura organizacional é constituída dos produtos que estão fora das mentes dos indivíduos, isto é, sagas, mitos, rituais e cerimônias etc. A dimensão subjetiva, por sua vez, representa os conteúdos tácitos introjetados e partilhados pelos indivíduos como valores, visões de mundo, significados e interpretações. Essas facetas da cultura organizacional encontram sustentação na perspectiva da cultura corporativa, na qual as organizações são concebidas como produtoras de artefatos ou elementos culturais que regulam e adaptam pessoas e organizações (SILVA; ZANELLI, 2004).

Com a premissa da cultura organizacional regular e adaptar pessoas e organizações, esse conceito passou a ser aplicado no campo da aprendizagem em organizações principalmente no final da década de 1990. Muitos autores cunharam o termo cultura de aprendizagem com o intuito de se estudar a dimensão social da aprendizagem (POPPER; LIPSHITZ, 1998; LIPSHITZ; POPPER; FRIEDMAN, 2002; ARMSTRONG; FOLEY, 2003). Entretanto, parece salutar afirmar que esse termo é inapropriado, visto que cultura é um construto fluido e abrangente, composto de diversas variáveis. Sendo assim, neste trabalho será utilizado o termo cultura organizacional orientada para a aprendizagem para o estudo da aprendizagem como um fenômeno social.

A cultura organizacional orientada para a aprendizagem é definida por Armstrong e Foley (2003) como um conjunto de crenças, valores, atitudes, papéis, suposições e comportamentos compartilhados que permitem a real aprendizagem na organização. Essa definição embasou o presente estudo, pois ressalta as dimensões objetiva (tangível) e subjetiva (intangível) da cultura, o que favorece a identificação de elementos culturais que dão suporte para a ocorrência da aprendizagem e contribui para a clarificação conceitual da aprendizagem em organizações.

Para Ellis et al. (1999) e Popper e Lipshitz (1998), cultura organizacional orientada para a aprendizagem é constituída dos seguintes valores: transparência, informação válida, orientação e responsabilidade. Para esses autores, transparência é a exposição de pensamentos e ações em relação ao outro na medida em que recebe feedback, informação válida é coletar e prover informações reconhecidas e suas implicações; orientação é focar na relevância da informação para o indivíduo, sem considerar seu padrão social; e responsabilidade é responsabilizar-se em aprender e implementar o que foi aprendido.

Cabe destacar que os valores da cultura organizacional orientada para a aprendizagem propostos por Ellis et al. (1999) e Popper e Lipshitz (1998) demonstram comportamentos de indivíduos comprometidos com a aprendizagem, mas também indicam normas sociais orientadas a aprendizagem existente em contextos organizacionais. Dessa forma, no presente estudo também abordou-se tais valores como comportamentos e normas sociais partilhados pelas pessoas na organização, visto que esses autores não apresentam o conceito de valores no contexto organizacional com amparo da literatura de valores individuais e organizacionais.

Ellis et al. (1999) realizaram um estudo para identificar as relações entre valores de aprendizagem e a percepção de erros críticos no trabalho. Esses autores utilizaram a mesma definição de Popper e Lipshitz (1998) em que a cultura organizacional orientada para a aprendizagem é formada por valores que representam comportamentos orientados à aprendizagem: transparência, informação válida, orientação e responsabilidade. A percepção de erros críticos, para Ellis et al. (1999), consiste na severidade dos custos conseqüentes de potenciais erros percebidos no trabalho. 
Esses autores validaram uma escala para aferição dos valores de aprendizagem (Learning Values Scale) e realizaram entrevistas para a identificação de erros críticos percebidos pelos sujeitos participantes da pesquisa. A amostra foi constituída por 262 funcionários, sendo 165 de 55 organizações (até 3 sujeitos de cada organização) dos setores público e privado para a fase um do estudo, e 102 para a fase 2. Na primeira fase da pesquisa, que envolveu a validação da escala de valores de aprendizagem, o resultado da análise fatorial revelou quatro fatores referentes aos valores transparência, informação válida, orientação e responsabilidade, constituídos por 35 itens, sendo 5, 9, 10 e 11 itens de cada fator, respectivamente.

Na segunda fase da pesquisa, Ellis et al. (1999) entrevistaram 102 participantes para identificar os erros críticos percebidos no trabalho. As entrevistas foram realizadas de acordo com os cargos dos participantes dessa fase da pesquisa: controladores de tráfego aéreo, gerentes de médio e alto nível, médicos e psiquiatras de um hospital psiquiátrico, e professores. Os autores da pesquisa identificaram os seguintes erros críticos:

- Controladores de tráfego aéreo: potencial perda de vidas;

- Gerentes de médio e alto nível: baixa eficiência econômica;

- Médicos e psiquiatras: prescrever ou administrar medicamentos ou tratamentos inapropriados;

- Professores: avaliar os comportamentos e realizações dos estudantes.

Os erros críticos percebidos foram classificados pelos autores em duas dimensões: severidade do erro e envolvimento versus imparcialidade em relação ao erro. Concluindo a pesquisa, Ellis et al. (1999) realizaram análises de variância (ANOVA), de tendência e contrastes analíticos com os resultados das fases 1 e 2. Esses autores identificaram que a percepção de erros críticos tem relação significante com os valores de aprendizagem. Em outras palavras, quanto mais o indivíduo percebe a possibilidade de erros graves no trabalho, maior é a internalização dos valores estudados, favorecendo a ocorrência do processo de aprendizagem em organizações, melhoria do desempenho individual e organizacional e diminuição da incidência de erros graves no trabalho.

A Learning Values Scale foi utilizada no estudo de Somech e Drach-Zahavy (2004) que tinha por objetivo investigar as relações entre comportamentos de cidadania organizacional e valores de aprendizagem. Os resultados mostraram que dois valores de aprendizagem, responsabilidade e informação válida, apresentaram relação positiva com os comportamentos de cidadania organizacional benéficos à organização. As relações encontradas por Somech e Drach-Zahavy (2004) entre cidadania organizacional e valores de aprendizagem reforçam a importância do desenvolvimento de um arcabouço teórico acerca da aprendizagem em organizações a partir de estudos que explorem as dimensões envolvidas nesse processo e suas relações com outras variáveis que impactam diretamente o desempenho de indivíduos e organizações.

\section{Método}

A escala de medida desenvolvida neste estudo originou da Learning Values Scale (LVS) validada por Ellis et al. (1999), a qual continha itens referentes comportamentos e normas sociais orientados a aprendizagem em organizações. Esses itens foram agrupados em 4 fatores denominados valores de aprendizagem: transparência, responsabilidade, orientação e informação válida.

Segundo esses autores, transparência reúne comportamentos de abertura para receber feedback; responsabilidade significa assumir o comportamento e suas conseqüências para a aprendizagem; orientação refere-se a abertura para avaliar as informações de modo impessoal; e, informação válida envolve comportamentos que visam a melhoria da objetividade e estrutura da informação considerada relevante à organização. A escala validada por Ellis et al. (1999) é constituída de 35 itens, sendo 5 itens para o fator transparência, 11 itens para o fator responsabilidade, 10 itens para o fator orientação e 9 itens para o fator informação válida. Destaca-se que essa escala foi desenvolvida originalmente na língua inglesa, o que demandou a tradução da mesma para o português por um especialista em língua inglesa e portuguesa. Cabe ressaltar que a escala original ainda não havia sido empregada no Brasil, bem como não há registros na literatura de que a LVS foi validada em outros idiomas ou países, tampouco se a mesma passou por novos processos de confirmação de sua estrutura fatorial.

Após a tradução dos itens, os mesmos foram avaliados com base nos critérios linguagem, ambigüidade, viés e ênfase sugeridos por Günther (1999), para identificar termos que pudessem prejudicar a compreensão dos respondentes. Com isso, a redação dos itens foi alterada para que a leitura e 
compreensão dos sujeitos participantes da pesquisa ocorressem de modo satisfatório, de acordo com a linguagem e cultura brasileira e da organização estudada.

Em adição, os itens repetidos foram retirados do instrumento, e aqueles que se referiam a dois ou mais objetos distintos em sua redação foram reescritos considerando o número de objetos destacados. Por último, itens relacionados a variáveis diferentes daquelas investigadas neste estudo também foram excluídos do conjunto.

Após essas análises iniciais dos itens, o instrumento foi formatado na versão para análise semântica com escala de concordância do tipo Likert, sendo 1 - Nunca Ocorre e 5 - Sempre Ocorre. A análise semântica ocorreu com a participação de onze funcionários da organização estudada, sendo esses de diferentes níveis hierárquicos e funcionais. O instrumento foi aplicado presencialmente, onde foi monitorado o tempo médio de resposta e registrou as sugestões dos participantes quanto à clareza, linguagem e nível de compreensão dos itens. Com essas informações, foram realizadas alterações na redação dos itens principalmente de acordo com as sugestões quanto a termos que melhor se adequavam a realidade da organização.

Por fim, o instrumento foi formatado em sua versão final para aplicação, constituída de vinte e sete itens sobre valores de aprendizagem em organizações, itens referentes à caracterização demográfica e funcional, além um campo dissertativo para registro de opiniões que os respondentes julgassem relevantes sobre o tema.

O instrumento de pesquisa foi disponibilizado aos membros da população-alvo do estudo por meio de uma página eletrônica, armazenada em um provedor de internet, através de um hiperlink de acesso enviado por correio eletrônico. Essa escolha se deu em função da realização da pesquisa pela rede mundial de computadores (internet), possibilitando uma melhor condição de abrangência e rapidez na coleta de dados.

A etapa de coleta de dados durou trinta e três dias, atingindo o número de 522 (quinhentos e vinte e dois) instrumentos válidos, perfazendo aproximadamente 9,57\% da população. Importa destacar que a pesquisa ocorreu com a participação de funcionários do quadro funcional da organização estudada, pertencentes às diretorias gerais e unidades sediadas em Brasília/DF, não sendo pesquisados os funcionários terceirizados e as demais diretorias e unidades de outras localidades do país, bem como funcionários lotados em agências.

De acordo com Pasquali (1999, 2005), os critérios de adequação da quantidade de respondentes aos propósitos de uma pesquisa são: de cinco a dez respondentes para cada item do instrumento, ou cem sujeitos para cada fator medido; ou pelo menos duzentos respondentes. Com base nessas recomendações, o presente estudo atendeu a dois critérios, tendo acima de 7 respondentes para cada item e 522 sujeitos participantes da pesquisa. Sendo assim, procedeu-se com as análises estatísticas descritivas e inferenciais.

\section{Resultados e Discussões}

Inicialmente, os dados foram registrados no programa SPSS (Statistical Package for the Social Sciences), versão 12.0. As análises descritivas e exploratórias para investigar a exatidão da entrada dos dados, a distribuição dos casos omissos, o tamanho da amostra, os casos extremos e a distribuição das variáveis não identificaram erros de digitação e mais de $5 \%$ de dados omissos em cada variável. Casos extremos univariados e multivariados foram pesquisados por meio dos escores Z e distância de Mahalanobis, respectivamente. Foram encontrados e retirados do banco de dados 16 casos extremos univariados. Não foram encontrados casos extremos multivariados. Sendo assim, a amostra final foi de 506 respondentes. Em adição, quanto à normalidade das respostas, poucos casos de assimetria e achatamento foram encontrados nas variáveis. Entretanto, não ocorreram transformações, pois Tabachnick e Fidell (2001) as contra-indicam neste tipo de estudo, podendo existir dificuldades na interpretação dos resultados.

A validação empírica da Escala de Valores de Aprendizagem em Organizações resultou das seguintes análises: componentes principais (PC - Principal Components) e método de fatoração dos eixos principais (PAF - Principal Axis Factoring). Segundo Pasquali (1997), as análises dos componentes principais e fatoriais aferem a validade em termos de fidedignidade de um instrumento de pesquisa. 
Dessa forma, procedeu-se com as análises dos componentes principais (PC) para estimar o número de fatores, identificar a ausência de multicolinearidade e analisar a fatorabilidade da matriz de correlações (PASQUALI, 2005). Em seguida, realizou-se as análises dos eixos principais (PAF) para obtenção de estruturas fatoriais. De acordo com Pasquali (2005) alguns critérios podem facilitar a decisão da quantidade de fatores a serem extraídos de um instrumento. Dentre eles, neste estudo foram utilizados os seguintes: valores próprios superiores a 1; análise de distribuição dos valores próprios (scree plot); cargas fatoriais acima de 0,35; análise dos índices de consistência interna dos itens (Alfa de Cronbach) e interpretabilidade das soluções propostas.

Gráfico 1 - Valores próprios da escala de valores de aprendizagem em organizações

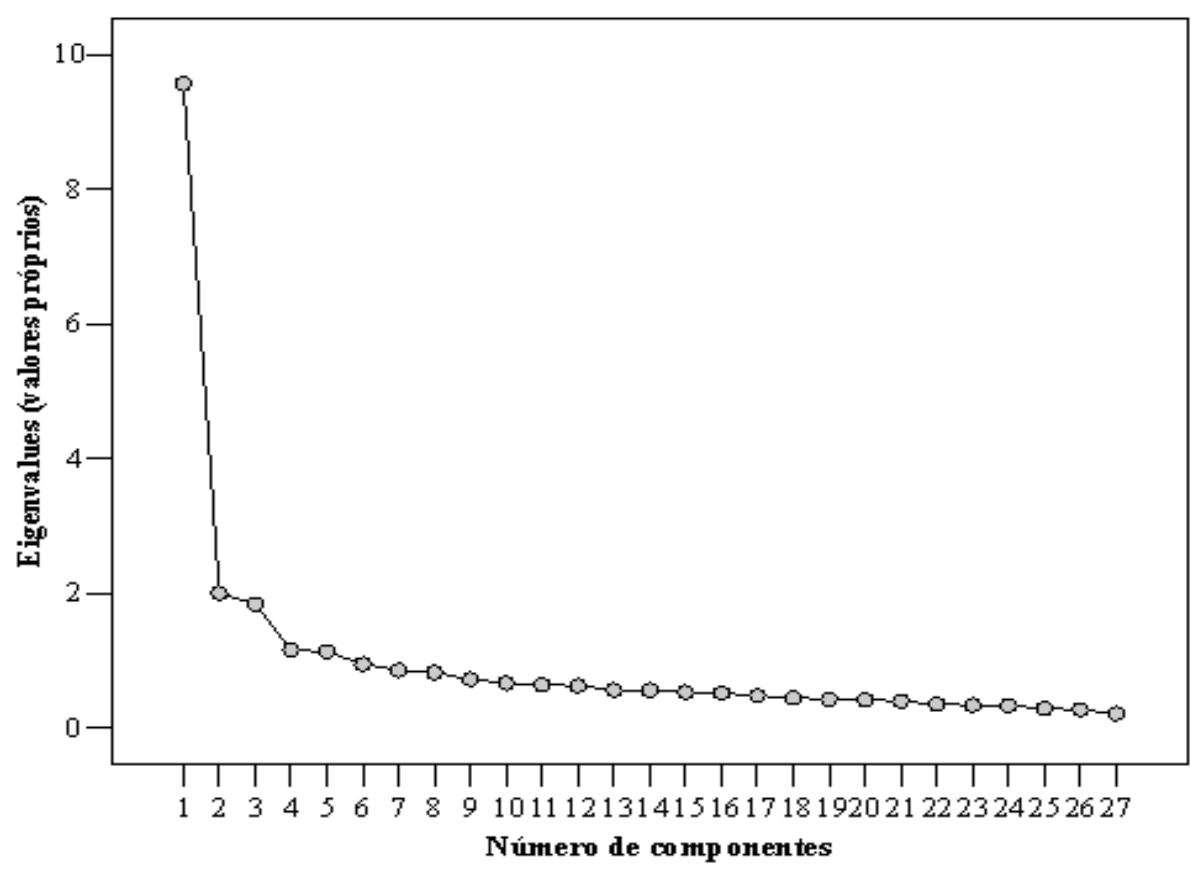

Fonte: dados da pesquisa.

Obteve-se o Kaiser-Meyer-Olkin (KMO) de 0,93 ( $p<0,000)$, considerado por Kaiser (1974, apud PASQUALI, 2005) excelente para adequação da amostra. O total de variância explicada foi de $53,60 \%$. Os resultados dessas análises indicaram soluções de 1 a 5 fatores; todas foram testadas com as análises fatoriais dos eixos principais ( $P A F$ - Principal Axis Factoring), com rotações Oblimin e Varimax, e de acordo com o critério de interpretabilidade (PASQUALI, 2005), optou-se pela solução de 3 fatores, com rotação Oblimin.

A tabela a seguir mostra a estrutura fatorial. Os itens com cargas iguais ou superiores a 0,35 também são apresentados, assim como suas comunalidades $\left(\mathrm{h}^{2}\right)$, os índices de consistência interna (Alfa de Cronbach), os eigenvalues (valores próprios), percentuais de variância explicada e médias e desviospadrão dos fatores.

Após as análises fatoriais, dois itens foram excluídos por não apresentarem carga fatorial satisfatória $(<0,35)$ para nenhum dos fatores extraídos. O Fator 1 foi denominado "Responsabilidade e Abertura à Aprendizagem" e definido como: "conjunto de comportamentos que refletem compromisso e disposição de indivíduos em aprender, identificar as causas de seus erros e mostrar iniciativa em desempenhar-se melhor no trabalho". 
Tabela 1 - Estrutura fatorial da escala de valores de aprendizagem em organizações.

\begin{tabular}{|c|c|c|c|}
\hline Ordem & $\mathrm{CF}$ & Descrição dos itens & $h^{2}$ \\
\hline 1 & 0,76 & $\begin{array}{l}\text { Item 14-Em minha equipe os funcionários assumem a responsabilidade } \\
\text { por suas ações. }\end{array}$ & 0,63 \\
\hline 2 & 0,74 & $\begin{array}{l}\text { Item 16-Quando um membro da minha equipe erra, ele verifica o que o } \\
\text { fez errar. }\end{array}$ & 0,58 \\
\hline 3 & 0,72 & $\begin{array}{l}\text { Item } 17-\text { Os membros da minha equipe aprendem com seus erros a fim de } \\
\text { serem melhores no futuro. }\end{array}$ & 0,60 \\
\hline 4 & 0,68 & $\begin{array}{l}\text { Item 22-Os membros da minha equipe informam ao chefe sobre os seus } \\
\text { (próprios) erros de trabalho. }\end{array}$ & 0,52 \\
\hline 5 & 0,66 & $\begin{array}{l}\text { Item 15-Em minha equipe os funcionários aprendem com os erros dos } \\
\text { outros. }\end{array}$ & 0,51 \\
\hline 6 & 0,65 & Item 8-Os membros da minha equipe admitem seus erros. & 0,56 \\
\hline 7 & 0,65 & Item 21-Em minha equipe, os funcionários dizem a verdade no trabalho. & 0,53 \\
\hline 8 & 0,63 & $\begin{array}{l}\text { Item 27-Os funcionários da minha equipe enfrentam os problemas de } \\
\text { trabalho. }\end{array}$ & 0,43 \\
\hline 9 & 0,59 & $\begin{array}{l}\text { Item 13-Os membros da minha equipe assumem responsabilidades } \\
\text { pessoais quando o grupo falha. }\end{array}$ & 0,33 \\
\hline 10 & 0,55 & $\begin{array}{l}\text { Item 9-Os funcionários da equipe a que pertenço contribuem em } \\
\text { discussões profissionais. }\end{array}$ & 0,47 \\
\hline 11 & 0,44 & $\begin{array}{l}\text { Item } 26 \text {-Os funcionários da minha equipe não mentem para defenderem a } \\
\text { si próprios. }\end{array}$ & 0,24 \\
\hline 12 & 0,42 & Item 24-Em minha equipe, os erros são discutidos abertamente. & 0,51 \\
\hline \multicolumn{2}{|c|}{ Eigenvalue $=9,57$} & \% da Variância Total = 38,28 & \\
\hline \multicolumn{2}{|c|}{ Alfa $=0,90$} & $N=475$ & \\
\hline \multicolumn{2}{|c|}{ Média $=3,40$} & Desvio-Padrão = 0,67 & \\
\hline
\end{tabular}

\begin{tabular}{|c|c|c|c|}
\hline Ordem & $\mathrm{CF}$ & Descrição dos itens & $h^{2}$ \\
\hline 1 & 0,58 & $\begin{array}{l}\text { Item 20-Quando funcionários da minha equipe não alcançam metas, eles } \\
\text { preferem guardar isso para si próprios. }\end{array}$ & 0,50 \\
\hline 2 & 0,55 & $\begin{array}{l}\text { Item 19-Os funcionários da minha equipe informam seus superiores de seus } \\
\text { sucessos, mas não de seus fracassos. }\end{array}$ & 0,47 \\
\hline 3 & 0,55 & $\begin{array}{l}\text { Item 23-Os membros da equipe a que pertenço preferem contar "meias } \\
\text { verdades" a fim de parecerem bem-sucedidos. }\end{array}$ & 0,57 \\
\hline 4 & 0,43 & $\begin{array}{l}\text { Item 18-Quando cometem erros, os membros da equipe em que trabalho } \\
\text { fornecem informações imprecisas. }\end{array}$ & 0,37 \\
\hline \multicolumn{2}{|c|}{ Eigenvalue $=2,00$} & \% da Variância Total $=8,00$ & \\
\hline \multicolumn{2}{|c|}{ Alfa $=0,78$} & $N=498$ & \\
\hline \multicolumn{2}{|c|}{ Média = 2,56 } & Desvio-Padrão = 0,81 & \\
\hline
\end{tabular}

Continua... 
Continuação...

\begin{tabular}{|c|c|c|c|}
\hline Ordem & CF & Descrição dos itens & $\mathbf{h}^{2}$ \\
\hline 1 & 0,71 & $\begin{array}{l}\text { Item 3-Em minha equipe de trabalho, as pessoas são encorajadas a dizer francamente o } \\
\text { que pensam. }\end{array}$ & 0,61 \\
\hline 2 & 0,66 & Item 1-Nas discussões em grupo, os participantes têm direitos iguais de falar. & 0,51 \\
\hline 3 & $-0,59$ & $\begin{array}{l}\text { Item } 4-O \text { chefe abusa da autoridade nas discussões referentes ao trabalho de minha } \\
\text { equipe. }\end{array}$ & 0,43 \\
\hline 4 & 0,59 & $\begin{array}{l}\text { Item 6-As ações da minha equipe de trabalho são julgadas por seus méritos, } \\
\text { independentemente de quem as executa. }\end{array}$ & 0,46 \\
\hline 5 & 0,58 & $\begin{array}{l}\text { Item 2-A organização enfatiza o que e porquê os erros acontecem, e não quem os } \\
\text { comete. }\end{array}$ & 0,44 \\
\hline 6 & $-0,53$ & Item 12-Em minha equipe o chefe nunca está errado. & 0,42 \\
\hline 7 & 0,53 & Item 11-Nossa norma é "estamos todos no mesmo barco, todos podem cometer erros". & 0,45 \\
\hline 8 & 0,52 & $\begin{array}{l}\text { Item 7-A organização encoraja a igualdade entre diferentes níveis hierárquicos nas } \\
\text { discussões profissionais. }\end{array}$ & 0,31 \\
\hline 9 & 0,47 & Item 25-Os erros são considerados naturais e legítimos em minha equipe. & 0,50 \\
\hline \multicolumn{2}{|c|}{ Eigenvalue $=1,83$} & \multicolumn{2}{|l|}{ \% da Variância Total = 7,32 } \\
\hline \multicolumn{2}{|c|}{ Alfa $=0,85$} & \multicolumn{2}{|l|}{$N=498$} \\
\hline \multicolumn{2}{|c|}{ Média = 3,38 } & \multicolumn{2}{|l|}{ Desvio-Padrão = 0,71 } \\
\hline
\end{tabular}

Fonte: dados da pesquisa.

O Fator 2 foi denominado “Transparência no Desempenho no Trabalho" e refere-se a: "comportamentos de funcionários e equipes de trabalho a respeito de falhas no desempenho no trabalho". De acordo com a Tabela 1, esse fator apresentou um Alfa de Cronbach igual a 0,78, com itens de carga fatorial entre 0,43 e 0,58. Conforme Pasquali (2005, os itens tiveram validade entre razoável e boa, mostrando que o fator apresenta certa confiabilidade para aferição dessas ações em organizações. Entretanto, é importante que outros estudos busquem melhorar esses escores a fim de se construir uma medida mais consistente, seja pela inserção de mais itens e/ou pela melhoria de sua redação.

A média desse fator foi $2,56(D P=0,81)$, podendo inferir que a percepção dos participantes indica ocorrência razoável de comportamentos não transparentes no trabalho. Isso mostra que os respondentes percebem que os membros de suas equipes assumem suas falhas no desempenho de suas atividades.

O Fator 3 foi denominado "Integridade e Igualdade no Trabalho" e definido como: "conjunto de comportamentos orientados para construção de um ambiente de trabalho receptivo a opiniões, compreensão de erros e igualitário". Conforme a Tabela 1, o Alfa de Cronbach desse fator é 0,85 e a cargas fatoriais variaram de 0,47 a 0,71. Os itens apresentam validade de razoável a excelente (PASQUALI, 2005). Para calcular os escores fatoriais, os itens 4 e 12 foram invertidos, pois apresentaram cargas fatoriais de sentido negativo.

A média desse fator foi 3,38 (DP=0,71), indicando a ocorrência razoável desses comportamentos na organização. Pode-se inferir que os respondentes percebem que os funcionários de suas equipes se comportam de modo aberto ao feedback, às opiniões dos outros, e consideram erros naturais, assim como se dão o direito de expressarem seus pontos de vista.

De posse desses resultados, observa-se que a Escala de Valores de Aprendizagem em Organizações mostrou-se válida do ponto de vista empírico, sendo aplicável em contextos organizacionais brasileiros com intuito de se identificar a percepção de indivíduos acerca da ocorrência de comportamentos orientados à aprendizagem. 


\section{Conclusões e Recomendações}

Os resultados obtidos neste estudo indicaram que a estrutura fatorial (3 fatores) explicou 53,60\% da variância total das respostas dos pesquisados à escala. Os alfas de Cronbach mostraram-se, em geral, excelentes. Entretanto, cabe ressaltar que o alfa do Fator Transparência no Desempenho no Trabalho $(0,78)$ merece atenção, pois indica a importância de se melhorar seu escore fatorial para que se torne mais fortemente fidedigno. Sugere-se a realização de entrevistas com indivíduos de diferentes contextos organizacionais para captação de diferentes percepções, e, com isso, itens mais precisos sejam elaborados.

Os dados indicaram, portanto, que a Escala de Valores de Aprendizagem em Organizações constitui em instrumento válido e fidedigno para a realidade brasileira, e que pode ser utilizado para fins de pesquisa, diagnóstico e intervenção na área de aprendizagem em organizações. Importa destacar que a organização dispõe, de forma geral, de um ambiente favorável à aprendizagem na medida em que, segundo a percepção dos respondentes, as pessoas se comportam de modo responsável e receptivo em relação à aprendizagem, mostram-se transparentes em relação aos erros e insucessos no trabalho, bem como reconhecem um contexto de igualdade e integridade na organização.

A partir deste estudo pode-se delinear algumas considerações em relação a pesquisas futuras para que se desenvolva a literatura de aprendizagem em organizações em termos cumulativos. Tendo em vista que a escala validada refere-se a comportamentos e normas sociais de uma cultura organizacional orientada para a aprendizagem, é importante que novas pesquisas investiguem artefatos culturais, especialmente valores individuais e organizacionais, crenças, rituais alinhados com os pressupostos da aprendizagem. Em adição, percebe-se a relevância de se replicar essa escala em outros contextos organizacionais, permitindo uma análise de diferentes características que interferem na percepção dos valores de aprendizagem em organizações.

Ressalta-se a importância de se realizar estudos longitudinais para desenvolvimento de modelos explicativos do processo de aprendizagem em organizações, destacando o papel dos valores de aprendizagem para a geração de resultados individuais e organizacionais que favorecem a aquisição e manutenção de vantagens competitivas. Empreender estudos qualitativos para aferição de antecedentes e resultados advindos da aprendizagem em organizações torna-se indispensável para a compreensão desse processo como um todo, evidenciando variáveis determinantes de sua ocorrência. Por fim, destaca-se a relevância de se verificar variáveis preditoras dos valores de aprendizagem em organizações para elucidar com clareza a diversidade conceitual presente na literatura e identificar variáveis constituintes do comportamento organizacional que contribuem fortemente para a aprendizagem.

\section{Referências}

ARMSTRONG, A.; FOLEY, P. Foundations for a learning organization: organizational learning mechanisms. The Learning Organization, v. 10, n. 2/3, p. 74-82, 2003. doi:10.1108/09696470910462085.

BASTOS, A. V. B.; GONDIM, S. M. G.; LOIOLA, E. Aprendizagem organizacional versus organizações que aprendem: características e desafios que cercam essas duas abordagens de pesquisa. Revista de Administração da USP, v. 39, n. 3, p. 220-230, jul./ago./set., 2004.

DUNCAN, W. J. Organizational culture: 'getting a fix' on an elusive concept. The Academy of Management Executive, v. 3, n. 3, p. 229-236, 1989.

EASTERBY-SMITH, M. Disciplines of organizational learning: contributions e critiques. Human Relations, v. 50, n. 9, p. 1085-1113, 1997. doi:10.1177/001872679705000903.

; ARAUJO, L. Aprendizagem organizacional: oportunidades e debates. In: EASTERBY-SMITH, M; BURGOYNE, J.; ARAUJO, L. (Orgs.). Aprendizagem organizacional e organização que aprende: desenvolvimento na teoria e na prática. São Paulo: Atlas, p. 15-34, 2001.

ELLIS, S.; CARIDI, O.; LIPSHITZ, R.; POPPER, M. Perceived error criticality and organizational learning: an empirical investigation. Knowledge and Process Management, v. 6, n. 3, p. 166-175, 1999. doi:10.1002/(SICI)1099-1441(199909)6:3<166::AID-KPM65>3.0.CO;2-S.

GARVIN, D. A. Aprendizagem em ação: um guia para transformar sua empresa em uma learning organization. Rio de Janeiro: Qualitymark, 2002. 
GHERARDI, S.; NICOLINI, D. The sociological foundations of organizational learning. In: DIERKES, M.; ANTAL, A. B.; CHILD, J.; NONAKA, I. Handbook of organizational learning and knowledge. Oxford: Oxford University Press, 2003. p. 35-60.

GÜNTHER, H. Como elaborar um questionário. In: PAQUALI, L. (Org.) Instrumentos psicológicos: manual prático de elaboração. Brasília: LabPAM, 1999. p. 231-258.

HOFSTEDE, G.; NEUIJEN, B.; OHAYV, D. D.; SANDERS, G. Measuring organizational cultures: a qualitative and quantitative study across twenty cases. Administrative Science Quarterly, v. 35, n. 2, p. 286-316, 1990. doi:10.2307/2393392.

HOFSTEDE, G. Culturas e organizações: compreender a nossa programação mental. Lisboa: Silabo, 1991.

ISIDRO-FILHO, A. Mecanismos e cultura de aprendizagem em organizações: análise de suas relações com liderança em uma organização financeira. 2006. 140f. Dissertação (Mestrado em Administração) Universidade de Brasília, Brasília.

LIPSHITZ, R.; POPPER, M.; FRIEDMAN, V. J. A multifacet model of organizational learning. The Journal of Applied Behavioral Science, v. 38, n.1, p. 78-98, 2002. doi:10.1177/0021886302381005.

NONAKA, I.; TAKEUCHI, H. Criação de conhecimento na empresa: como as empresas japonesas geram a dinâmica da inovação. 14. ed. Rio de Janeiro: Campus, 1997.

PASQUALI, L. Psicometria: teoria e aplicações. Brasília: Universidade de Brasília, 1997.

Testes referentes a construto: teoria e modelo de construção. In: PASQUALI, L. (Org.). Instrumentos psicológicos: manual prático de elaboração. Brasília: LabPAM, 1999. p. 37-72.

Análise fatorial para pesquisadores. Brasília: LabPam \& UnB, 2005.

POPPER, M.; LIPSHITZ. Organizational learning mechanisms: a structural and cultural approach to organizational learning. The Journal of Applied Behavioral Science, v. 34, n. 2, p. 161-179, 1998. doi:10.1177/0021886398342003.

SILVA, N.; ZANELLI, J. C. Cultura organizacional. In: ZANELLI, J. C.; BORGES-ANDRADE, J. E.; BASTOS, A. V. B. (Orgs.). Psicologia, organizações e trabalho no Brasil. Porto Alegre: Artmed, 2004. p. 407-442.

SOMECH, A.; DRACH-ZAHAVY, A. Exploring organizational citizenship behaviour from an organizational perspective: the relationship between organizational learning and organizational citizenship behaviour. Journal of Occupational and Organizational Psychology, v. 77, p. 281-298, 2004. doi:10.1348/0963179041752709.

TABACHNICK, B. G.; FIDELL, L. S. Using multivariate statistics. New York: HarperCollins College Publishers, 2001.

TROMPENAARS, F. Nas ondas da cultura: como entender a diversidade cultural nos negócios. São Paulo: Educator, 1994.

WEICK, K. E.; WESTLEY, F. Organizational learning: affirming an oxymoron. In: CLEGG, S. R.; HARDY, C.; NORD, W. R. (Eds.). Handbook of organization studies. London: Sage, 1996. p. 440-458.

WILPERT, B. Organizational behavior. Annual Review of Psychology, v. 46, p. 59-90, 1995. doi:10.1146/annurev.ps.46.020195.000423. PMid:18767984. 